\title{
Composite elastomeric materials filled with modified mineral fillers
}

\author{
Ahmadjon Ibadullayev ", Elmira Teshabayeva, Bakhadir Kakharov, and Dilnoza Nigmatova \\ Tashkent State Transport University, Tashkent, Uzbekistan
}

\begin{abstract}
In the paper, the influence of modified Angren kaolin on the properties of composite elastomeric materials based on butadiene-styrene rubber has been established that the addition of modified Angren kaolin into rubber mixtures instead of gas pedals, activators and mineral fillers causes intensive connection of sulfur with macromolecules. Adsorbed sulfur on the surface of particles of modified Angren kaolin and its uniform distribution in the composition and formation of the structure with equal force were determined. This effect shows that the modified Angren kaolin in the curing processes accelerates and activates and affects the formation of the curing grid with equal strength and helps distribution throughout the composite. It has been established that introduction of MAK into the composition of elastomers more than 50 wt. \% per 100 wt. \% of rubber changes technological and technical properties of composite elastomeric materials. The application of modified Angren kaolin instead of the gas pedal, activator of vulcanization and mineral filler in composite elastomeric materials allows making rubber goods of various purposes.
\end{abstract}

\section{Introduction}

The application of organic gas pedals has introduced the essential changes into the process of rubber vulcanization. They considerably improve technical properties of vulcanizates, increase ageing resistance of rubber articles, make it possible to obtain homogeneous mass articles, reduce the duration of vulcanization; as a result, the number of equipment and energy consumption decreases several times, and the labor productivity increases $[1,2]$.

It is known that many gas pedals are mutually activated during vulcanization. Using various gas pedal systems, it is possible to influence the properties of vulcanizates: to change the "rubber-stretch" curve, increase the tension at a certain elongation, and increase the strength properties even in the absence of reinforcing fillers. Organic gas pedals are active in vulcanization in the presence of some metal oxides and hydroxides. Metal oxides have the most effective effect in the presence of fatty acids [3-5]. As a rule, the vulcanization process is largely determined by the nature and character of vulcanization gas pedals. In most cases, the properties of gas pedals are characterized by their chemical structure. It was found that the presence of electron acceptor functional groups, such as $\mathrm{N}$, $\mathrm{O}, \mathrm{S}$, favorably affects the efficiency of gas pedals $[6,7]$.

\footnotetext{
* Corresponding author: ibadullaev1957@bk.ru
} 
A polymeric gas pedal $[2,8,9]$ for vulcanization of rubber mixtures from a combination of isoprene and butadiene rubbers, obtained by polycondensation of hexamethylenediamine with sulphur in the presence of methylpyrrolidone as a solvent, was synthesized. This produces a high molecular weight product soluble in methylpyrrolidone, dimethyl sulfoxide. Based on kinetic studies, it was found that the synthesized polymer is a gas pedal, which provides a wide plateau of vulcanization and thus improves the physical and mechanical properties of vulcanizates.

Many organic compounds [10-12] are known to accelerate the process of sulfur vulcanization, i.e. the process of interaction of rubber with sulfur. However, the main requirement for vulcanizing systems is a high vulcanizing activity with the absence of premature vulcanization in temperature conditions of technological processing of rubber mixtures - rather limits the list of gas pedals of vulcanization, which have found wide industrial application.

In the light of the above, the aim is to create modified, highly effective vulcanization gas pedals for composite elastomeric materials based on butadiene-styrene rubber.

\section{Materials and Methods}

Butadiene styrene rubber was used as a standard rubber compound. Angren kaolin as a modifier Nitrogen, phosphorus-containing organic gas pedal (APOA), secondary absorbent alkanolamines (AAA) and a combination of APOA were chosen as the investigated filler: WAA (1:1) (CU). Rubber mixtures were made on laboratory mixing rollers RC-WW $150 / 330$ (Rubicon, Germany). Determination of Muni viscosity of rubber mixtures was carried out on a Muni MV 2000 viscometer (Alpha Technologies, England). The stress relaxation test is performed on the same samples as the Mooney viscosity immediately after the viscosity measurement is completed by stopping the rotor rotation quickly and measuring the drop in the final Mooney viscosity over time. The kinetics of rubber compound vulcanization was determined on an ODR 2000 rheometer (Alpha Technologies, UK). Technical indicators were determined according to the relevant GOSTs.

\section{Results and Discussion}

Qualitative and quantitative changes in the rubber mixture during vulcanization are due to the course of several physical and chemical processes, leading to the lubrication, as a rule, by the strong chemical bonds of rubber molecules between each other, which ultimately forms a spatial grid in the rubber mass. The spatial structure formed during vulcanization depends on many factors, but the composition of the rubber mixture and the conditions of vulcanization (temperature, external pressure and duration) are the determining ones [13$15]$.

The greatest effect of vulcanization is achieved when organic gas pedals are used together with its activators - some oxides and hydroxides of metals. The main activator in rubber technology is zinc oxide, which due to its amphoteric nature, promotes the formation of optimal actual agents of vulcanization during the mixing of rubbers. Additions give a better quality of rubbers to the recipe of the so-called secondary activators-fatty acids stearic, oleic and others, which are also involved in the formation of sulfur complexes and reactions associated with them. Adsorbent-alkanolamine, a secondary raw material of oil and gas production, was chosen as a vulcanizing agent. The following alkanolamines are used to purify oil and gas from acid gases (H2S, CO2) (Table 1). 
Table 1. Physicochemical properties of initial and spent alkanolamines

\begin{tabular}{|c|c|c|c|c|c|}
\hline $\begin{array}{c}\text { Source and } \\
\text { spent alkanol- } \\
\text { amino }\end{array}$ & \multicolumn{2}{|c|}{ concentration } & \multirow{2}{*}{\begin{tabular}{c} 
Boiling Point \\
\cline { 2 - 3 }$(180 \mathrm{kPa}){ }^{\circ} \mathrm{C}$
\end{tabular}} & $\begin{array}{c}\text { Freezing } \\
\text { temperature } \\
{ }^{\circ} \mathrm{C}\end{array}$ & $\begin{array}{c}0{ }^{\circ} \mathrm{C}, \\
103 \mathrm{~Pa} \cdot \mathrm{c}\end{array}$ \\
\hline MEA & 2.5 & 15 & 170 & -5 & 1.0 \\
\hline WMEA & 2.5 & 65 & 183 & -11 & 1.6 \\
\hline DEA & 2 & 21 & 280 & -5 & 1.3 \\
\hline WDEA & 2 & 71 & 291 & -12 & 2.0 \\
\hline MDEA & 2 & 24 & 248 & -6 & 1.06 \\
\hline WMDEA & 2 & 74 & 266 & -14 & 2.9 \\
\hline
\end{tabular}

*MEA is monoethanolamine; WMEA is waste monoethanolamine; DEA is diethanolamine; WDEA is waste diethanolamine; MDEA is methyldiethanolamine; WMDEA is waste methyldiethanolamine.

The table shows that the change in the physical and chemical properties of secondary alkanolamines due to the absorption of acid gases from the composition of natural gas, i.e. the boiling point and viscosity increased and the freezing point decreased. The study and their composition showed that they mainly consist of absorbed acid gases and their compounds (H2S, CO2, CO and others). Based on this, we decided to use secondary alkanolamines in the production of composite elastomeric materials as a gas pedal of rubber vulcanization.

Studies have shown that by adding 3 wt.\% per 100 wt.\% of rubber secondary alkanolamines in the composition of butadiene-styrene rubbers, the beginning of the vulcanization process increases, the time of vulcanization decreases and the density of the vulcanization network increases (Fig.1-3). In this case, secondary alkanolamines are recommended for the vulcanization of thin-layer fine rubber products.

The influence of phosphated fatty acid alkanolamides derived from the secondary raw material of cotton oil processing - gossypol resin on rubber vulcanization kinetics has been studied. The molecular weight of phosphatized fatty acid alkylamides is 1100-1200.

The study of their composition by infrared spectroscopy showed that at 900, 1070, 1210,1310 and $1370 \mathrm{~cm}-1 ; 2360,2930$ and $3300 \mathrm{~cm}-1$, there are absorption bands, which belong to the following functional groups $\mathrm{CO},-\mathrm{N}, \equiv \mathrm{R}=\mathrm{O},=\mathrm{O}, \mathrm{N}-\mathrm{H}$, which predetermined the possibility of using them as vulcanizing organic gas pedals. Application of phosphated alkylamide fatty acids as vulcanizing agents in the process of composite elastomeric materials has shown that increasing its content increases the time of the beginning of vulcanization; it makes it possible to obtain rubber products and tires with large dimensions and complex patterns (Figure 1-2).

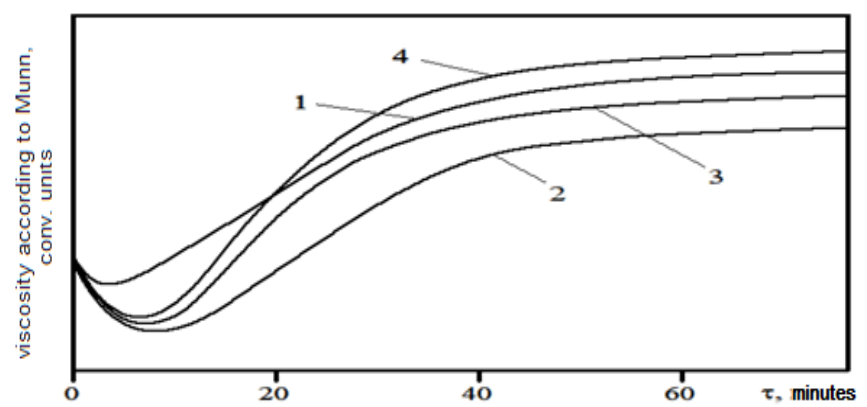

Fig. 1. Influence of gas pedals on vulcanization kinetics of rubber mixtures based on butadienestyrene rubber: 1 is DPG; 2 is PFAA; 3 is spent alkanolamine; 4 is PFAA + spent alkanolamine 
It has been established that secondary alkylolamines accelerate the initiation of vulcanization, while phosphated fatty acid alkylamides retard the initiation of rubber vulcanization. To increase the activity of alkylolamines, they were modified with phosphated fatty acid alkylamides and mixed in a 1:1 ratio at $318-323 \mathrm{~K}$ for 30 minutes resulting in the formation of a colloidal system.

The obtained modified compositions were added to butadiene-styrene rubber, and their influence on the vulcanization process was studied. When sulfur vulcanizing systems instead of diphenylguanidine (DPG) were added, the vulcanization time decreased in comparison with the use of secondary alkylolamines, while in the case of the addition of phosphated fatty acid alkylamides, the vulcanization time increased; hence the developed modified MDF can be used as a vulcanization accelerator (Fig. 1-4).

It is known that composites containing metal oxides can be used as an activator of rubber vulcanization. In this connection, we studied the physicochemical properties of Angren kaolin (Table 2).

It is seen from the table that modified Angren kaolin consists mainly of SiO2, A12O3, $\mathrm{TiO} 2, \mathrm{SaO}, \mathrm{MgO}, \mathrm{Fe} 2 \mathrm{O} 3$ and $\mathrm{FeO}$, whose general formula is $\mathrm{A} 12 \mathrm{O} 3-2 \mathrm{SiO} 2-2 \mathrm{H} 2 \mathrm{O}$. Angren kaolin contains metal oxides; therefore, it can be used simultaneously as a vulcanization activator and a filler in composite elastomer materials (Table 3).

From the table, it is seen that at addition Angren kaolin $40 \mathrm{wt} \% \%$ and $5 \mathrm{wt} . \%$ zinc oxide per $100 \mathrm{wt} . \%$ of rubber instead of Elenin kaolin (EC), the physical and mechanical properties of vulcanizates are increased by $10-15 \%$, but the thermal ageing $(100 \mathrm{oC}$ at 72 hours) is $0.4 \%$, while with Elenin kaolin this index is $0.6 \%$. Research has shown without adding activators to the composition of rubber mixtures; it is possible to obtain rubber with high physical and mechanical properties with Angren kaolin; it is explained by containing metal oxides in the composition of Angren kaolin [16, 17].

Table 2. Chemical properties of Angren kaolin

\begin{tabular}{|c|c|c|c|c|c|c|c|c|c|c|c|}
\hline \multicolumn{10}{|c|}{ Indicators, \% } \\
\hline $\mathrm{SiO}_{2}$ & $\mathrm{Al}_{2} \mathrm{O}_{3}$ & $\mathrm{TiO}_{2}$ & $\mathrm{CaO}$ & $\mathrm{MgO}$ & $\mathrm{FeO}$ & $\mathrm{Fe}_{2} \mathrm{O}_{3}$ & $\mathrm{SO}_{3}$ & $\mathrm{Cl}^{-}$ & $\begin{array}{c}\mathrm{SO}_{4}^{-} \\
2\end{array}$ & $\begin{array}{c}\text { Water- } \\
\text { soluble } \\
\text { salts }\end{array}$ & $\begin{array}{c}\text { Humi- } \\
\text { dity }\end{array}$ \\
\hline 51.20 & 43.40 & 0.60 & 0.21 & 0.30 & 1.2 & 1.02 & 0.21 & 0.01 & 0.05 & 0.10 & 1.7 \\
\hline
\end{tabular}

Table 3. Effect of $40 \mathrm{wt} \%$ Angren kaolin on the physical and mechanical properties of a standard rubber compound based on butadiene-styrene rubber

\begin{tabular}{|c|c|c|c|c|}
\hline № & Indicators & $\begin{array}{c}40 \text { wt.h. } \mathrm{EC}+5 \\
\text { wt.h. } \mathrm{ZnO}\end{array}$ & $\begin{array}{c}40 \text { wt.h. } \mathrm{AK}+5 \\
\text { wt.h. } \mathrm{ZnO}\end{array}$ & $\begin{array}{c}40 \text { wt.h. } \\
\mathrm{AK}\end{array}$ \\
\hline 1 & Tearing strength, $\mathrm{MPa}$ & 9.6 & 10.2 & 9.1 \\
\hline 2 & Tensile tear, mm & 340 & 360 & 380 \\
\hline 3 & Residual elongation, mm & 20 & 20 & 22 \\
\hline 4 & Tear strength, MPa & 0.8 & 0.7 & 0.7 \\
\hline 5 & $\begin{array}{c}\text { Thermal aging coefficient, } \\
100^{\circ} \mathrm{C}, 72 \text { hours }\end{array}$ & 0.6 & 0.4 & 0.2 \\
\hline
\end{tabular}

For the application of Angren kaolin (AK) in composite elastomeric materials, it is possible to apply two methods: firstly to reduce metal oxides from the composition of Angren kaolin according to requirements of GOST (0,3\%); however, it is impossible because $1,02 \% \mathrm{FeO}$ which cannot be cleaned by existing technologies, in this connection we applied the second method of modification, it was modified by 5-10-15 wt. P. with 
modified alkylolamines and studied the effect on the kinetics of vulcanization of rubber mixtures, technological and physical-mechanical properties of rubbers from the standard recipe was removed gas pedal, and activator of vulcanization, as well as the filler, instead of them, were added modified Angren kaolin (MAK).

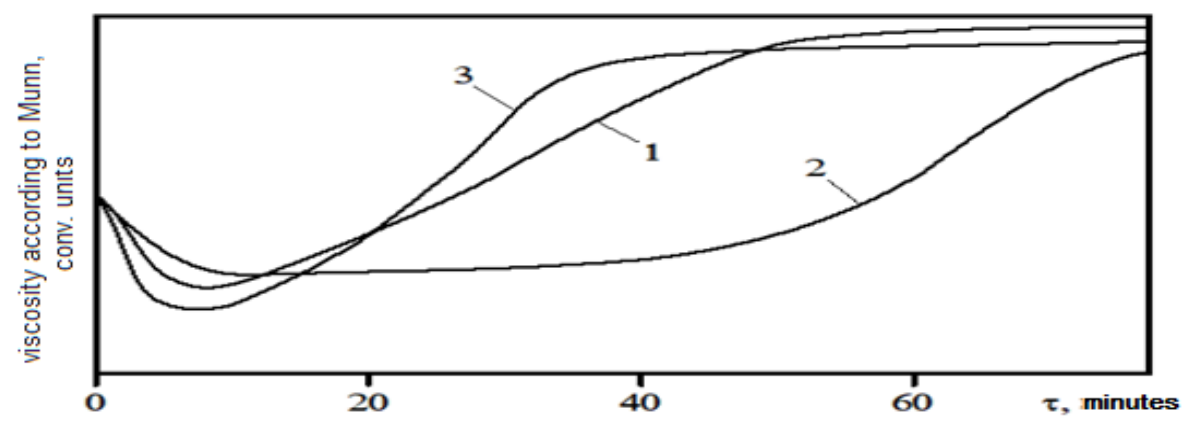

1 is standard recipe; 2 is 40 wt. $\%$. AK; 3 is 40 wt. $\%$. MAK.

Figure 2: Effect of the ingredients on the curing kinetics of the rubber mixture based on butadienestyrene rubber.

The addition of $40 \mathrm{wt} . \%$ of butadiene-styrene rubber per $100 \mathrm{wt} . \%$ of caoutchouc at the beginning - end and the density of curing matrix correspond to the standard formulation (Fig.2). The results of the investigation of technological and physical-mechanical properties were determined, and it was shown that heat aging meets the standard requirements (Table 4).

Table 4. Effect of modified Angren kaolin on the physical and mechanical properties of rubber based on butadiene-styrene rubber

\begin{tabular}{|c|c|c|c|c|}
\hline № & Indicators & Standard recipe & $\begin{array}{c}40 \text { wt.h. } \\
\text { AK }\end{array}$ & 40 wt.h. IAC \\
\hline 1. & Tensile strength, MPa & 9.6 & 9.1 & 11.4 \\
\hline 2. & Tensile rupture, $\mathrm{mm}$ & 340 & 380 & 320 \\
\hline 3. & Residual elongation, $\mathrm{mm}$ & 20 & 22 & 18 \\
\hline 4. & $\begin{array}{c}\text { Thermal aging coefficient, } 373 \\
\text { K, } 72 \text { hours }\end{array}$ & 0.4 & 0.2 & 0.8 \\
\hline
\end{tabular}

Thus the application of modified Angren kaolin with $10 \mathrm{wt} \%$ modified secondary alkanolamine forms a complex with iron oxides, which do not affect the thermal aging of vulcanizates. In contrast, the filling of rubber mixtures with modified Angren kaolin allows to a reduction in the formulation activator and gas pedal of vulcanization, as well as mineral filler.

The research has shown that when modified Angren kaolin $[18,19]$ is added to rubber mixtures based on butadiene-styrene rubbers instead of gas pedals, activators and mineral fillers, the connection of sulfur with macromolecules is intensive. Sulfur adsorbed on the surface of particles of modified Angren kaolin and its uniform distribution in the composition and formation of the structure with the same force were determined. This effect shows that the modified Angren kaolin in the curing processes accelerates and activates and influences the formation of the curing grid with equal strength and helps the distribution throughout the composite. 
The advantage of modified Angren kaolin over the separate application of gas pedals, activators and fillers is that the vulcanization process at high temperatures forms a vulcanization grid with the same action forces. For example, a vulcanization temperature of $413-433 \mathrm{~K}$ gives a reversion and increases the optimum of vulcanization and evenly distributes the vulcanization mesh in the composite volume.

In addition, separately vulcanizing agents and fillers, these indicators are unevenly distributed on the volume of vulcanizates. In this case, the study of the influence of modified Angren kaolin on the kinetics of vulcanization of elastomers and formation of transverse bonds and their properties showed that at vulcanization of composites, the structure of transverse bonds responsible for the durability of rubbers is formed. They are distributed uniformly on volume, it leads to high operational properties of rubber products and heat resistance (Table 5).

The introduction of modified Angren kaolin into the composition of elastomers increases the formation of transverse bonds compared with the introduction of unmodified Angren kaolin. This is confirmed by an increase in transverse bonds and a decrease in polysulfidity of the vulcanization network. The possibility of reducing the intensity of the ageing of rubbers and the intensity of active transverse bonds at filling with modified Angren kaolin compared with unmodified serially applied mineral fillers (Yelinsky kaolin, talc), is shown by structure Angren kaolin and modifiers. In this connection, we assume that modifiers based on alkanolamines and alkyloamides of phosphated fatty acids play a role in inhibiting donor-acceptor bond with the interaction of active centers and play a great role in the formation of vulcanization mesh, properties of vulcanization elastomeric composites at thermal, photodestruction [20-25].

Table 5. Influence of the ingredients on the properties of the formed bonds in the rubber-based on butadiene-styrene rubber. (Vulcanization time 40 minutes $416 \mathrm{~K}$, aging $373 \mathrm{~K} 72$ hours)

\begin{tabular}{|c|c|c|c|c|c|c|}
\hline \multirow{2}{*}{ Name } & \multicolumn{3}{|c|}{ The connections that are formed, \% } & $\begin{array}{c}\mathrm{F}_{\mathrm{p}}, \\
\text { MРa }\end{array}$ & $\begin{array}{c}\mathrm{K}_{\mathrm{T}} \text {, } \\
\text { ус. ед. }\end{array}$ \\
\cline { 2 - 7 } & -C-S $_{\mathrm{x}}$-C- & -C-S-S-C- & -C-S-C- & -C-C- & & \\
\hline Standard recipe & 32 & 34 & 24 & 10 & 11.2 & 0.66 \\
\hline Filled prescription with AK & 36 & 29 & 25 & 10 & 8.6 & 0.51 \\
\hline Filled recipe with IAC & 29 & 25 & 24 & 22 & 12.1 & 0.88 \\
\hline
\end{tabular}

Observed in the study of thermal aging of rubbers filled with modified Angren kaolin with increasing thermal aging time, relative elongation decreases and hardness increases compared to stabilized rubbers with neozone - $D$. It is shown that during thermal aging of rubbers, additional structures are formed, hardness increases and relative elongation decreases, due to sulfur, nitrogen, phosphorous compounds in secondary alkylolamine and phosphated alkyl amides of fatty acids.

To study the effect of modified Angren kaolin on the plastoelastic properties of composite elastomeric materials, a standard recipe based on butadiene-styrene rubbers has been developed. Activators, vulcanization gas pedals and carbon black were removed from the standard recipe. They were used only for comparison of the obtained results. It is known that physical and chemical properties of the structure, composition and quantity of ingredients form the main properties of composite elastomeric materials.

Technological properties of elastomeric compositions filled with modified Angren kaolin do not differ from those filled with commercially used mineral fillers. However, at adding MAK to elastomer composition more than 50 wt. $\%$ per 100 wt. $\%$ of rubber, technological properties of composite elastomer materials change (Fig. 3). Therefore it is 
necessary to regulate the technological properties of composite elastomeric materials by changing the content of ingredients in product formulations

As a result, the use of modified Angren kaolin plays the role of multifunctional ingredients, namely gas pedal, an activator of vulcanization and filler of composite elastomeric material, which in turn leads to reducing the time of manufacture of rubber mixtures and adjusting the structure and physical and mechanical properties of composites and products based on them.

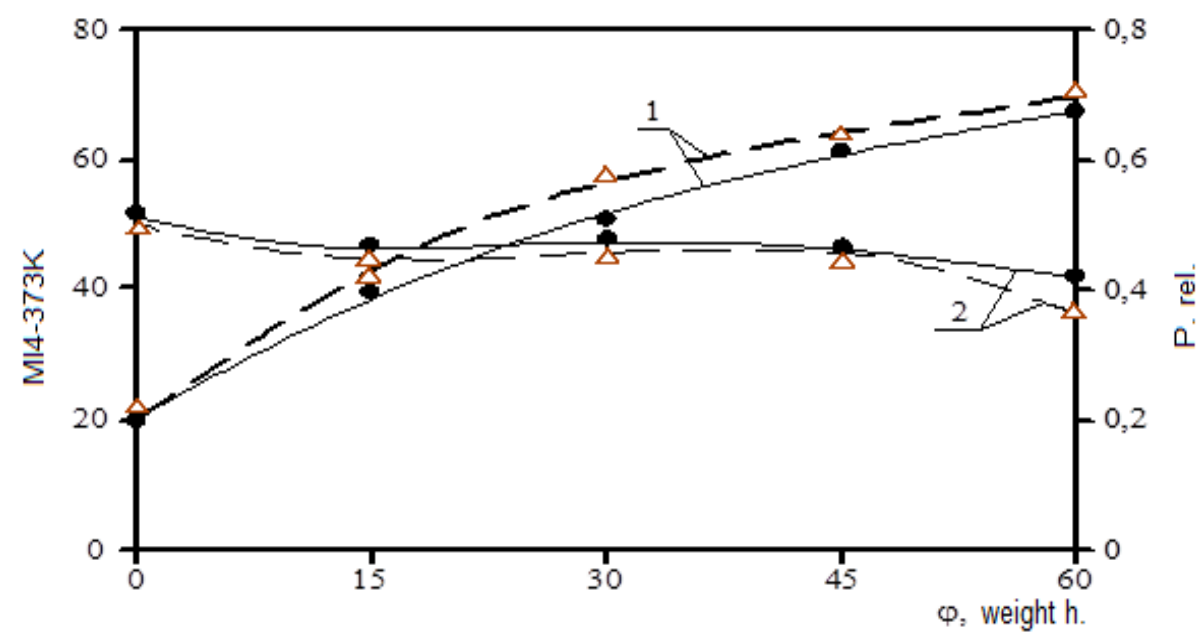

Fig. 3. Dependence of rubber compound plasticity (P) and Muni viscosity (ML4-373K) on the amount of butadiene styrene rubber-based filler: (-) is standard recipe, $(----)$ is recipe filled with MAK.

It has been determined that the addition of modified Angren kaolin into the composition of elastomeric composition based on butadiene-styrene rubbers increases elongation strength by $100-300 \%$ tensile strength in comparison with compositions filled with original kaolin. This is explained by the fact that the oligomeric cover on the surface of the modified Angren kaolin gives the possibility of uniform distribution of the ingredients in the composition, and it is also confirmed by the tear resistance properties of the elastomeric compositions. For example, when adding the modified Angren kaolin 40-60 wt.\% per 100 wt. $\%$ of butadiene-styrene rubber, the index equals $93.4 \mathrm{kN} / \mathrm{mg}$. Dynamic properties of rubbers, the addition of modified Angren kaolin improves and its content in the composition of 40-60 wt.h. per 100 wt.h. of rubber.

\section{Conclusions}

Thus, the results of studies on the effect of modified Angren kaolin on the properties of composite elastomeric materials based on butadiene-styrene rubber have established that the addition of modified Angren kaolin into the composition of rubber mixtures instead of gas pedals, activators and mineral fillers causes sulfur to connect with macromolecules intensively. Sulfur adsorbed on the surface of particles of modified Angren kaolin and its uniform distribution in the composition and formation of a structure with equal strength have been determined. This effect shows that the modified Angren kaolin in the curing processes accelerates and activates and influences the formation of the curing grid with equal strength and helps the distribution throughout the composite. It is established that 
introducing MAK into the composition of elastomers with more than $50 \mathrm{wt} . \%$ per $100 \mathrm{wt} . \%$ of rubber leads to changes in technological and technical properties of composite elastomer materials. Therefore it is necessary to regulate the technological properties of composite elastomeric materials by changing the content of ingredients in the product formulations. Application of modified Angren kaolin instead of the gas pedal, vulcanization activator and mineral filler in composite elastomeric materials makes it possible to produce rubber products for various purposes.

\section{References}

1. W.-J. Chen, B.-Q. Li, C.-X. Zhao, M. Zhao, T.-Q. Yuan, R.-C. Sun, J.-Q. Huang Q. Zhang, Electrolyte regulation towards stable lithium metal anode in lithiumsulfur batteries with sulfurized polyacrylonitrile cathode, Angew. Chem. (2019) https://doi.org/10.1002/ange.201912701.

2. B. Zhang, X. Qin, G.R. Li, X.P. Gao, Enhancement of long stability of sulfur cathode by encapsulating sulfur into micropores of carbon spheres, Energy Environ. 1531 (3). (2010)

3. A.K. Haridas, J. Heo, X. Li, H.-J. Ahn, X. Zhao, Z. Deng, M. Agostini, A. Matic, J.H. Ahn. A flexible and free-standing FeS/sulfurized polyacrylonitrile hybrid anode material for high-rate sodium-ion storage, Chem. Eng. J. (2019)

4. J. Wang, J. Yang, J. Xie, N. Xu, A novel conductive polymer-sulfur composite cathode material for rechargeable lithium batteries, Adv. Mater. 14 pp.13-14, (2002)

5. Yusupbekov A.Kh., Ibadullaev A., Abdurashidov T.R., Akhmedov, K.S. International Symposium on Flow-Induced Vibration and Noise.Acoustic Phenomena and Interaction in Shear Flows over Compliant and Vibrating Surfaces, Chemical technology, 301(3), pp. 79-80, (1988)

6. Negmatov N.S., Ziyamukhamedova U.A., Kuluev A.R. Antifriction materials and water-soluble compounds on basis of polymers for reducing the mechanical damage of cotton fibers. Plasticheskie Massy: Sintez Svojstva Pererabotka Primenenie, (1), pp. 42-45,(2002)

7. Umarov A., Kamalova D., Investigation of ultrafine expansion in Epr studies of a polymer composition based on polystyrene, AIP Conference Proceedings, 2308, (2020)

8. Y. Liu, W. Wang, A. Wang, Z. Jin, H. Zhao, Y. Yang, Effect of vapor pressure on performance of sulfurized polyacrylonitrile cathodes for Li/S batteries, RSC Adv. 6 pp. 106625-106630, (2016)

9. N. Bukit, E.M. Ginting, I.S. Pardede, E. Frida, B.F. Bukit, Mechanical properties of composite thermoplastic hdpe/natural rubber and palm oil boiler ash as a filler, J. Phys. Conf. Ser. 1120, 012003, https://doi.org/10.1088/1742-6596/1120/1/012003 pp.1-8. (2018)

10. E.M. Ginting, N. Bukit, GultomD. Motlan, E. Frida, B.F. Bukit, Preparation and characterization of oil palm empty bunches powder as A filler of polypropylene/ natural rubber, Int. J. Civ. Eng. Technol, 10 (6), pp. 453-464., (2019)

11. N.N. Myint, T.T. Aye, K.M. Naing, N. Wynn, Performance study of the natural rubber composite with clay minerals, J. Myan. Acad. Arts Sci. 6 (1), pp. 151-159, (2008)

12. Ziyamukhamedova U., Djumabaev D., Shaymardanov B. Mechanic chemical modification method used in the development of new composite materials based on epoxy binder and natural minerals, Turkish journal of Chemistry. 37(1). pp.51- 56. AnkaraTurkey, (2013) 
13. S. Phrommedetch, C. Pattamaprom, Compatibility improvement of rice husk and bagasse ashes with natural rubber by molten-state maleation, Eur. J. Sci. Res. 43 (3), pp. 411-416. (2010)

14. N. Bukit, E. Frida, The effect zeolite addition in $\mathrm{n}$ atural rubber polypropylene composite on mechanical, structure, and thermal characteristics, Makara J. Technol. 7 (3) pp 113-130, (2013).

15. H. Ismail, T.B. Khoon, N. Hayeemasae, S. Huseinsyah, Effect of palm ash on properties of polypropylene/recycled natural rubber gloves/oil palm ash composites, Bioresources 10 (1) pp 1495-1505. (2015).

16. Ziyamukhamedova U.A., Bakirov L.Y., Rakhmatov E.A., Bektemirov B.Sh. Structure and properties of heterocomposite polymeric materials and coatings from them obtained by heliotechnological method / International Journal of Recent Technology and Engineering 3(8), pp. 399-402, (2019)

17. Ibadullaev A., Yusupbekov A.Kh., Gorbunov V.A., Abdurashidov T.R. Reactivity of a secondary carbonaceous raw material with respect to carbon dioxide, Journal of applied chemistry of the USSR, 59, pp. 2387-2389, (1986)

18. Panitchakarn P., Wikranvanich J., Phisalaphong M. Synthesis and characterization of natural rubber/coal fly ash composites via latex aqueous microdispersion, J. Mater. Cycles Waste Manag. 21, pp. 134-144, (2019)

19. Vapaev M.D., Akhmadzhonov S.A., Teshabaeva E.U., Ibadullayev A. Investigation of modified angren caoline as filling and activator of vulcanization of some elastomeric compositions, Austrian Journal of Technical and Natural Sciences Austria, № 9-10,pp.29-33, (2018)

20. Kattakulov F., Muslimov T., Khusainov A., Vokhidov O., Sultanov S. Water resource saving in irrigation networks through improving the efficiency of reinforced concrete coatings, IOP Conference Series: Materials Science and Engineering, 883(1), 012053, (2020)

21. Kaharov B.B., Nigmatova D.I., Teshabaeva E.U. Secondary raw materials of oil and gas production adsorbent-alkanolamines as gas pedals of rubber vulcanization, International conference "Innovations in the oil and gas industry, modern power engineering and actual problems", Tashkent. pp. 679-680, (2020)

22. Akhmadjonov S, Vapaev M.D., Teshabaeva E.U. Organic gas pedals vulcanization for rubbers, All-Russian School-Conference of Young Scientists "Fundamental Sciences Specialist of the new century" with international participation in 20 - 24 April 2020. Ivanova. p. 230. (2020)

23. Rybakov V., Jos V., Raimova I., and Kudryavtsev K. Modal analysis of frameless arches made of thin-walled steel profiles. IOP Conf. Ser. Mater. Sci. Eng. 883, (2020).

24. Teshabaeva E.U., Seydabdullaev Y., Ibodullaev A. S. Investigation of effect of phosphotated alkylolamides of fatty acids on formation of structure of vulcanizational mesh and properties of composites. Austrian Journal of Technical and Natural Sciences Austria № 3-4, pp.92-96б (2016)

25. Ibadullaev A., Teshabaeva E.U., Tadzhibaeva G.S. Modification of secondary Angren kaolin and its influence on the properties of rubbers, Scientific-technical and production journal "Mining Vestnik of Uzbekistan", pp. 34-35, Tashkent, (2008) 